\title{
BRASSICA CROPS AND A STREPTOMYCES SP. AS POTENTIAL BIOCONTROL FOR CLUBROOT OF BRASSICAS
}

\author{
L-H. CHEAH ${ }^{1}$, G. KENT ${ }^{1}$ and S. GOWERS ${ }^{2}$ \\ ${ }^{1}$ Crop \& Food Research, Private Bag 11 600, Palmerston North \\ ${ }^{2}$ Crop \& Food Research, Private Bag 4704, Christchurch \\ Corresponding author: cheahl@crop.cri.nz.
}

\begin{abstract}
Two glasshouse experiments and a field trial were carried out to evaluate the potential of brassica crops which contain high levels of glucosinolates for control of clubroot of brassicas. Brassica rapa crops were grown for about 70 days in a field which was infested with Plasmodiophora brassicae. In the first glasshouse experiment, the leaf and stem of the plants were harvested, chopped into small pieces and mixed with clubrootinfested soil in punnets. Chinese cabbage seedlings were then transplanted into the punnets. In the second glasshouse experiment, soil samples were taken in punnets from plots where the $B$. rapa crops had been rotary hoed and left to decompose for about three weeks. Chinese cabbage seedlings were transplanted into the punnets. In both experiments, $B$. rapa-treated soil reduced $(\mathrm{P}<0.001)$ the clubroot severity on the root systems of the seedlings compared to the untreated control. A field trial was carried out on clubroot-infested soil to evaluate B. rapa, B. napus and a Streptomyces $\mathrm{sp}$. for clubroot control. The two brassicas crops and Streptomyces sp. reduced $(\mathrm{P}=0.05)$ clubroot severity on root systems of Chinese cabbage plants, except where B. napus was planted at a lower rate $\left(8\right.$ plants $\left./ \mathrm{m}^{2}\right)$. Keywords: Brassica spp., biocontrol, biofumigant, Streptomyces sp., clubroot.
\end{abstract}

\section{INTRODUCTION}

Clubroot of brassicas, caused by Plasmodiophora brassicae (Woronin), is the most serious disease of New Zealand's brassica growing areas, reducing marketable yields and sometimes totally destroying crops. Once the disease has established in the ground, it is very difficult to eradicate.

Good progress has been made towards controlling clubroot through the use of chemicals (Cheah 1995; Cheah et al. 1999), disease-resistant cultivars (Falloon et al. 1997) and biological control (Cheah et al. 2000a). We have also identified Brassica spp. having high levels of glucosinolates that could be used as a component of an integrated disease management strategy for clubroot. The negative impact of Brassica tissue on harmful soil micro-organisms is well documented (Chan \& Close 1987; Kirkegaard et al. 1994) and has been reviewed by Brown \& Morra (1997).

This paper reports the results of a glasshouse test and field trial to evaluate the potential of two species of Brassica as biofumigants and a Streptomyces sp. as a biocontrol agent for the control of clubroot. These two Brassica species were screened and selected for their high levels of glucosinolates in plant tissues by Crop \& Food Research at Lincoln.

\section{Glasshouse experiment 1}

\section{MATERIALS AND METHODS}

Brassica rapa L. (turnip) plants were grown for about 70 days in a commercial field plot which was severely infested with the clubroot pathogen. It was found that the root 
systems of these plants were not infected by the disease. Leaves and stems of these plants were taken and chopped into small $(1-5 \mathrm{~mm})$ pieces. Eighty grams (fresh weight) of this plant material was mixed with $250 \mathrm{~g}$ clubroot infested soil in a punnet. Eight Chinese cabbage seedlings cv. Wong Bok (14 days old) were transplanted into a punnet and kept under intermittent mist in a glasshouse $\left(25^{\circ} \mathrm{C}\right)$ for 5 weeks until disease assessment. Control seedlings were grown in unamended field soil. The treatments were replicated five times.

Disease was assessed by removing the seedlings from each punnet, washing the root systems and visually scoring them for clubroot severity $(0=$ healthy root systems to $5=$ completely clubbed).

\section{Glasshouse experiment 2}

Brassica rapa plants were grown (16 plants $\left./ \mathrm{m}^{2}\right)$ for about 70 days in a commercial field plot which were severely infested with clubroot pathogen. The plants were then ploughed and rotary-hoed (12 cm deep) into the soil. The plant materials were left to decompose for 3 weeks. The treated soil was taken and placed in punnets. Eight Chinese cabbage seedlings (14 days old) were transplanted into a punnet and kept under intermittent mist in a glasshouse $\left(25^{\circ} \mathrm{C}\right)$ for 5 weeks until disease assessment. Control seedlings grew in untreated soil. The treatments were replicated five times. Disease was assessed as in experiment 1.

\section{Field trial}

A field trial was carried out at a commercial grower's property on clubroot-infested soil (pH 6.5) in Palmerston North. Seedlings of B. rapa and B. napus L. (rape) were transplanted into field plots and grown for about 70 days. Two planting densities ( 8 and 16 plants $/ \mathrm{m}^{2}$ ) were used for each species (Table 1). The plants were then ploughed and rotary hoed into the soil to a depth of $12 \mathrm{~cm}$. The plant materials were left to decompose for 3-4 weeks.

A. Streptomyces sp. (S99) which has been shown to give significant control of clubroot (Cheah et al. 2000a) was also included in this trial. This isolate was cultured and grown in autoclaved crush maize in plastic bags for 4 weeks at $22^{\circ} \mathrm{C}$. The concentration of the inoculum was about $20 \times 10^{8}$ colony forming units $/ \mathrm{cm}^{3}$. The crush-maize inoculum was spread on the soil surface of each plot (about $500 \mathrm{~g} / \mathrm{m}^{2}$ ) and incorporated by rotary hoeing to a depth of about $12 \mathrm{~cm}$.

Chinese cabbage cv. Wong Bok seedlings were transplanted into trial plots. Control plots had not contained Brassica plants. The trial design was a randomized complete block with six replicates, each consisting of six treatments. Each treatment plot consisted of a single row of 10 plants spaced at $0.3 \mathrm{~m}$. Crop management followed routine commercial practices.

Plants were harvested from each plot at maturity (14 weeks). All root systems were lifted and scored for clubroot on a $0-5$ scale, where $0=$ healthy root system and $5=$ complete clubbing on the whole tap root. Data were analysed using ANOVA procedures of the Genstat 5 statistical package. Field data were logarithmically transformed to perform analysis of variance and back-transformed.

\section{Glasshouse experiment 1}

\section{RESULTS}

Chinese cabbage seedlings grown in soil with chopped $B$. rapa tissues had a mean root score of $0.6(\mathrm{SEM}=0.1)$. This was a lower $(\mathrm{P}<0.001)$ clubroot severity than the untreated control seedlings (mean $=3.4$, SEM=0.2).

\section{Glasshouse experiment 2}

The clubroot disease severity on root systems was generally low. Seedlings of Chinese cabbage grown in soil that was treated with $B$. rapa had a mean clubroot score of 0.2 $(\mathrm{SEM}=0.1)$, which was less $(\mathrm{P}<0.001)$ than the untreated control seedlings $($ mean $=1.5$, SEM=0.5)

Field trial

The disease level on root systems of Chinese cabbage plants was low. All treatments (except treatment 3 ) reduced $(\mathrm{P}=0.05)$ clubroot severity on root systems compared to 
the untreated control (Table 1). Brassica napus at the lower rate $\left(8\right.$ plants $\left./ \mathrm{m}^{2}\right)$ was not significantly different from the untreated control. No phytotoxicity was observed on the treated plants.

TABLE 1: Mean clubroot score on root systems of Chinese cabbage after soil treatment with Brassica spp. and Streptomyces sp. in field trial.

\begin{tabular}{lccc}
\hline Treatment & Rate $\left(\right.$ plant $\left./ \mathrm{m}^{2}\right)$ & Mean root score & $\begin{array}{c}\text { Logarithm of mean } \\
\text { root score }^{2}\end{array}$ \\
\hline 1. B. rapa & 8 & 0.6 & -0.55 \\
2. B. rapa & 16 & 0.6 & -0.47 \\
3. B. napus & 8 & 0.8 & -0.24 \\
4. B. napus & 16 & 0.6 & -0.45 \\
5. S99 & & 0.6 & -0.50 \\
6. Untreated & & 1.4 & 0.32 \\
LSD $(\mathrm{P}=0.05 ; \mathrm{df}=25)$ & & & 0.66 \\
\hline
\end{tabular}

${ }^{1}$ Clubroot score: $0=$ healthy root system, $5=$ complete clubbing on the tap root. These figures are the back-transformed means of root score rounded to 1 decimal place.

${ }^{2}$ Data were logarithmically transformed to perform analysis of variance.

\section{DISCUSSION}

Both glasshouse experiments and the field trial showed that all treatments reduced the clubroot severity on root systems of Chinese cabbage plants, indicating that these Brassica spp. are potentially good candidates for biofumigants for the control of clubroot.

Our results support past findings that Brassica tissues actively suppress soilborne diseases (Brown \& Morra 1997). Chan \& Close (1987) reported that in glasshouse tests, B. napus and four species of Brassica reduced the root rot severity and Aphanomyces euteiches Drechsler oospore numbers on peas. In a field trial they also found that these Brassica spp. reduced the Aphanomyces root rot.

The mechanism of biofumigant action against clubroot involved is not fully understood. However, glucosinolates, a group of thioglycosides that are present within the tissue of Brassica, are thought to be involved (Fenwick et al. 1994). After tissue damage, glucosinolate molecules are cleaved by a thioglucosidase, producing many products including isothiocyanates, nitriles and thiocyanates. Isothiocyanates are biologically active, disrupting cellular components by denaturing protein structure (Kawakishi et al. 1983). However, there may be other factors involved in reducing clubroot severity.

In this trial, Streptomyces sp. (S99) was shown to reduce the clubroot severity, confirming our previous findings (Cheah et al. 2000a).

Our results indicate that the B. rapa and B. napus tested, and a Streptomyces sp. (S99), can provide an additional control strategy for integrated disease management for clubroot. Other methods including cultural practices, liming, resistant cultivars and chemicals (Cheah et al. 2000b) should also be used for control of clubroot.

\section{REFERENCES}

Brown, P.D.; Morra, M.J. 1997: Control of soil borne plant posts using glucosinolatecontaining plants. In: Sparks, D.L. ed. Advances in agronomy, Vol. 61. Academic Press, San Diego, CA. Pp. 167-231.

Chan, M.K.Y.; Close, R.C. 1987: Aphanomyces root rot of peas. 3. Control by the use of cruciferous amendments. N.Z. J. Agric. Res. 30: 224-233. 
Cheah, L-H. 1995: Calcium Cyanamide $\left(\mathrm{CaCN}_{2}\right)$ for Clubroot Control in Cauliflower. Proc. $10^{\text {th }}$ Australasian Plant Path. Conf.: 99.

Cheah, L-H.; Page, B.B.C.; Koolaard, J.P.; Falloon, R.E. 1999: Clubroot control on Chinese cabbage. NZ Commercial Grower 54 (1): 27.

Cheah, L-H.; Veerakone, S.; Kent, G. 2000a: Biological control of clubroot on cauliflower with Trichoderma and Streptomyces spp. N.Z. Plant Prot. 53: 18-21.

Cheah, L-H.; Porter, I.; Donald, C.; Falloon, R.E. 2000b: Clubroot hits the road. NZ Commercial Grower 55(4): 15-17.

Falloon, R.E.; Nott, H.; Cheah, L-H.; Wright, P.; Gower, S. 1997: Integrated control offers best prospects. NZ Commercial Grower 52(3): 20-22.

Fenwick, G.R.; Heany, R.K.; Mullin, W. 1994: Glucosinolates and their breakdown products in food and food plants. CRC Crit. Rev. Food Sci. Nutr. 18: 123-201.

Kawakishi, S.; Goto, T.; Namiki, M. 1983: Oxidative scission of the disulfide bond of cysteine and polypeptides by the action of allyl isothiocyanate. Agric. Biol. Chem. 47: 2071-2076.

Kirkegaard, J.A.; Gardner, P.A.; Angus, J.F.; Koetz, E. 1994: Effect of Brassica break crops on the growth and yield of wheat. Aust. J. Agric. Res. 45: 529-545. 